\title{
Grating-based X-ray tomography of 3D food structures
}

\author{
Miklos, Rikke; Nielsen, Mikkel Schou; Einarsdottir, Hildur; Lametsch, Rene
}

Published in:

Proceedings of the 19th International ESAFORM Conference on Material Forming (ESAFORM 2016)

Link to article, DOI:

$10.1063 / 1.4963604$

Publication date:

2016

Document Version

Publisher's PDF, also known as Version of record

Link back to DTU Orbit

Citation (APA):

Miklos, R., Nielsen, M. S., Einarsdottir, H., \& Lametsch, R. (2016). Grating-based X-ray tomography of 3D food structures. In Proceedings of the 19th International ESAFORM Conference on Material Forming (ESAFORM 2016) (pp. 1-5). [180001] American Institute of Physics. A I P Conference Proceedings Series Vol. 1769 https://doi.org/10.1063/1.4963604

\section{General rights}

Copyright and moral rights for the publications made accessible in the public portal are retained by the authors and/or other copyright owners and it is a condition of accessing publications that users recognise and abide by the legal requirements associated with these rights.

- Users may download and print one copy of any publication from the public portal for the purpose of private study or research.

- You may not further distribute the material or use it for any profit-making activity or commercial gain

- You may freely distribute the URL identifying the publication in the public portal 


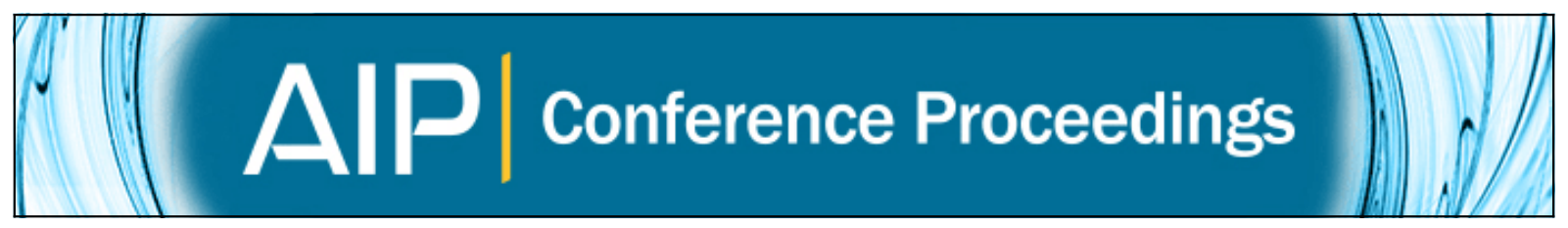

\section{Grating-based X-ray tomography of 3D food structures}

Rikke Miklos, Mikkel Schou Nielsen, Hildur Einarsdottir, and René Lametsch

Citation: AIP Conference Proceedings 1769, 180001 (2016); doi: 10.1063/1.4963604

View online: http://dx.doi.org/10.1063/1.4963604

View Table of Contents: http://scitation.aip.org/content/aip/proceeding/aipcp/1769?ver=pdfcov

Published by the AIP Publishing

Articles you may be interested in

Noise properties of grating-based $\mathrm{x}$-ray phase contrast computed tomography

Med. Phys. 38, S106 (2011); 10.1118/1.3532396

Noise in x-ray grating-based phase-contrast imaging

Med. Phys. 38, 4133 (2011); 10.1118/1.3592935

Beam hardening effects in grating-based $x$-ray phase-contrast imaging

Med. Phys. 38, 1189 (2011); 10.1118/1.3553408

A grating-based single-shot x-ray phase contrast and diffraction method for in vivo imaging

Med. Phys. 37, 6047 (2010); 10.1118/1.3501311

Quantitative grating-based x-ray dark-field computed tomography

Appl. Phys. Lett. 95, 094105 (2009); 10.1063/1.3213557 


\title{
Grating-based X-ray Tomography of 3D Food Structures
}

\author{
Rikke Miklos ${ }^{1, a)}$, Mikkel Schou Nielsen², b), Hildur Einarsdottir ${ }^{3, c)}$, René \\ Lametsch $^{1, \mathrm{~d})}$ \\ ${ }^{I}$ Department of Food Science, Faculty of Science, University of Copenhagen, Frederiksberg C, Denmark \\ ${ }^{2}$ Niels Bohr Institute, Faculty of Science, University of Copenhagen, Copenhagen, Denmark \\ ${ }^{3}$ Department of Applied Mathematics and Computer Science, Technical University of Denmark, Kgs. \\ Lyngby, Denmark \\ a)Corresponding author:miklos@food.ku.dk \\ b)schou@nbi.ku.dk \\ c)hildr@dtu.dk \\ d)rla@food.ku.dk
}

\begin{abstract}
A novel grating based X-ray phase-contrast tomographic method has been used to study how partly substitution of meat proteins with two different types of soy proteins affect the structure of the formed protein gel in meat emulsions. The measurements were performed at the Swiss synchrotron radiation light source using a grating interferometric set-up.
\end{abstract}

\section{INTRODUCTION}

During the last decades X-ray computed tomography (CT) has generated interest as a valuable method in non-destructive three-dimensional imaging of microstructure of food. X-ray $\mu \mathrm{CT}$ has been used in studies of a wide range of commodities including e.g. meat, fruits, cereals, coffee beans, dairy products, contributing to a better understanding of the physical structure of the samples (Schoeman et al., 2015). Further the non-destructive characteristics of the method add to the unique properties in order to visualize and quantify structural changes during processing of food as bubble growth and foam setting during bread making (Babin et al., 2006) or microstructural evolution of ice cream (Pinzer et al, 2012). The contrast in conventional absorption X-ray images are based on variation in the intensity caused by the differences in attenuation of the beam attributable to density and compositional differences in the sample. This limits the method to studies where a large difference in structural densities is expected.

Recently, a novel grating based X-ray tomographic method with increased contrast has been demonstrated (Bech et al., 2010a; Weitkamp et al., 2005). By use of grating interferometry, new modalities can be obtained simultaneously with absorption computed tomography (CT). These modalities are called phase contrast and dark field imaging, measuring the electron density and the diffusion length of a sample. The phase-contrast modality uses the refraction of X-rays caused by variation in electron densities for image generation, which results in improved contrast towards differences in mass density in soft tissues and serves to overcome challenges caused by similar attenuation properties of sample components. The superior contrast for soft tissues provided by X-ray phase-contrast CT compared to absorption CT has been demonstrated in a study of pork fat and rind (Jensen et al., 2011), in meat emulsions (Einarsdottir et al., 2014) and to study heat induced structural changes in meat (Miklos et al., 2015). The dark field modality measures the scattering of the beam giving information about ordered microstructures in the sample. The dark field modality has shown potential as way to detect freeze damages in berries (Nielsen et al., 2014)

The objective of this study was to use X-ray phase contrast tomography to investigate how substitution of meat proteins with two different types of soy proteins (derived from either isolate or concentrate) influences the microstructure of the protein network in meat emulsions. The measurements were performed at a synchrotron facility with a grating interferometric set-up. 


\section{X-RAY MODALITIES}

In Figure 1 the three types of physical interactions - absorption, refraction and scattering - used as imaging modalities in grating-based interferometry are illustrated. The effect on an incoming Gaussian shaped beam profile (black) is depicted when elements with different physical properties are measured. The profiles shown in color represent what is recorded when a material is present. In green, the effect from an absorptive material is shown to attenuate the beam, while in blue; the effect of a refractive material is seen to cause a transverse shift in the position of the beam profile. Lastly, the small-angle scattering from a material with ordered micro-structures causes the beam profile, here shown in red, to broaden. By separating the attenuation, transverse shift and broadening of the beam, it is thus possible to measure three complementary imaging modalities (Bech et al., 2010a; Pfeiffer, 2012).

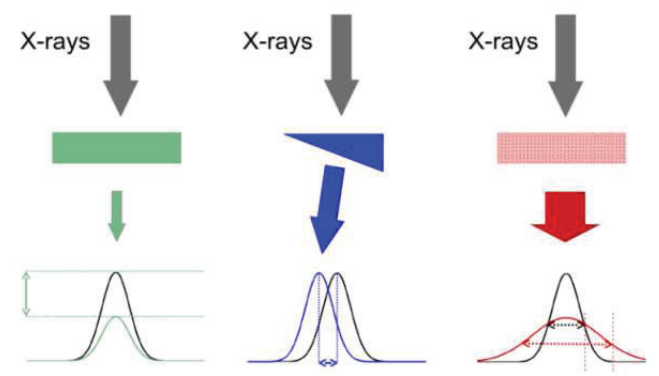

FIGURE 1. Three contrast mechanisms are used in grating-based imaging. Absorption: Attenuation of beam. Refraction (Phase contrast): Transverse shift of beam. Scattering (Dark field): Broadening of beam.

\section{GRATING-BASED INTERFEROMETRY}

One method to separate the three X-ray interactions is grating-based interferometry (GBI), which relies on an X-ray interferometer consisting of periodic gratings for measurements. A schematic of a setup for GBI is shown in Figure 2. Grating G1 produces a periodic intensity modulation, consisting of periodic fringes, transverse to the beam direction. The change in position, mean value and amplitude of the periodic fringes can be probed using a second grating, G2, by moving a grating in steps through the period in the pattern while recording an image at each step. From this series of scans, the absorption, refraction and small-angle scattering can be recorded by a detector with the same exposures giving an inherent voxel correspondence. In combination with tomography, this results in absorption, phasecontrast and dark-field image volumes, measuring the attenuation length, electron density and scattering of the sample, respectively (Bech et al., 2010b; Weitkamp et al., 2006). The method can be applied using polychromatic sources but a certain degree of spatial coherence is needed. In a laboratory setup, spatial coherence can be achieved either by using a micro focus source or by using a third grating G0, which acts as an array of line sources for use with source sizes up to a square millimeter.

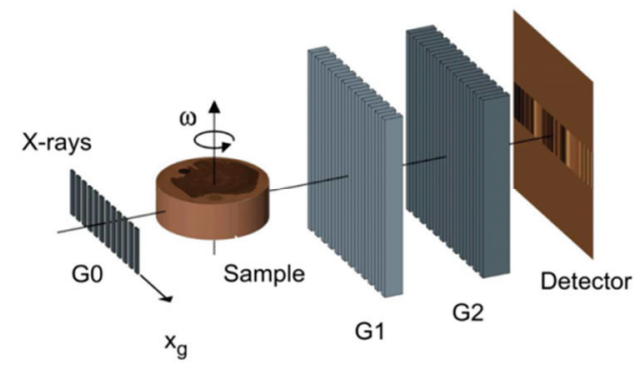

FIGURE 2. Schematic setup for GBI. Grating G1 creates a interference pattern analyzed by G2. Different parts of the interference pattern is analyzed by stepping G2. G0 is included in lab set-ups to ensure sufficient coherence. Reprinted from Nielsen et al. (2012) 


\section{Sample Preparation}

Meat emulsions were formulated to contain $12 \%$ protein, $20 \%$ lipid, $63 \%$ moisture, $2.5 \%$ salt and $2.5 \%$ dry ingredients. The protein consisted either entirely of meat proteins (control) or was substituted by one third with soy protein derived from soy concentrate. All ingredients (meat/soy, fat, ice, salt and dry ingredients) were comminuted to a meat batter. The batter was vacuum packed to avoid air and transferred into a $0.5 \mathrm{~mL}$ sample holder.

\section{X-ray Measurements and Data Processing}

Absorption and phase-contrast CT scans of the sample were obtained by use of a grating interferometer setup at the TOMCAT beam line, Swiss Light Source (SLS) at the Paul Scherrer Institute (PSI). The technique has been explained previously elsewhere (Bech et al., 2010a), and the setup is described in detail in McDonald et al. (2009). Measurements were made at photon energy of $25 \mathrm{keV}$ and the third Talbot fractional distance was used (Weitkamp et al., 2006) with a grating period of the phase-grating, called G1, of $3.9 \mu \mathrm{m}$ and a period of $2 \mu \mathrm{m}$ of the analyzer grating, called G2. The height of the grating lines was designed for photon energy of $25 \mathrm{keV}$. The sample was kept in a water bath during the measurements in order to reduce the difference in refractive index between the sample container and its surroundings. The scan time was around 90 minutes per tomogram. Each volume consisted of $2560 \mathrm{x}$ $2560 \times 1400$ pixels with a voxel size of $3.25 \times 3.25 \times 3.25 \mu \mathrm{m}$.

The X-ray tomograms were reconstructed at the TOMCAT beam line using a local implementation of the filtered back-projection algorithm for absorption and phase-contrast tomography as described in Pfeiffer et al. (2007).

\section{RESULTS AND DISCUSSION}

To demonstrate the difference in image quality between the absorption and the phase contrast modality an example of an absorption and phase contrast image of transverse cut of a raw emulsion prepared with soy isolate is presented in Figure 3. The greyscale images are reconstructed from a single slice of the data sets. The dark ring surrounding the samples is the sample tube. The total width of the images corresponds to $8 \mathrm{~mm}$. Scale bar at image B is $5 \mathrm{~mm}$. The absorption image (Fig $3 \mathrm{~A}$ ) appears noisy and hardly any contrast between the sample components is seen. In comparison, superior contrast is provided in the phase contrast images (Fig $3 \mathrm{~B}$ ). In the phase contrast image intensity differences reflect differences in electron density of the structural components where the light intensity increases with increasing densities. The protein phase (grey), fat (dark), salt (white spots) appear clearly separated and even density variations within the protein phase is observed.
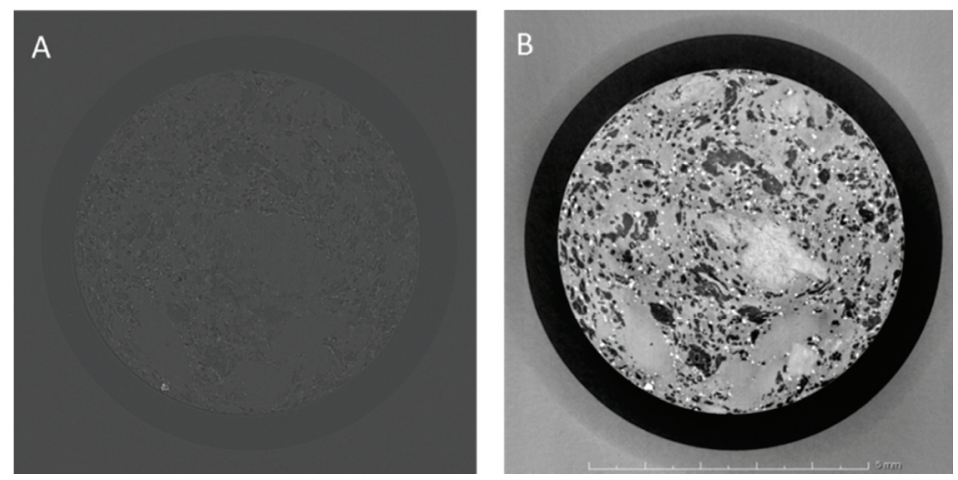

FIGURE 3. Greyscale images of reconstructed single slices of the absorption (a) and phase contrast (B) data sets. The dark ring surrounding the samples is the sample tube. In the absorption image (A) hardly any contrast between the sample components is seen. In the phase contrast images (B), the samples components are separated due to differences in electron densities: protein phase (grey), fat (dark), salt (white spots). Scale bar at image B is $5 \mathrm{~mm}$. Total length of image corresponds to $8 \mathrm{~mm}$. 
In Figure 4 a 3D visualization of the reconstructed phase contrast data set of the heat treated control emulsion ( Fig 4 A) and the emulsions prepared with soy isolate (Fig 4 B) or soy concentrate (Fig 4 C).

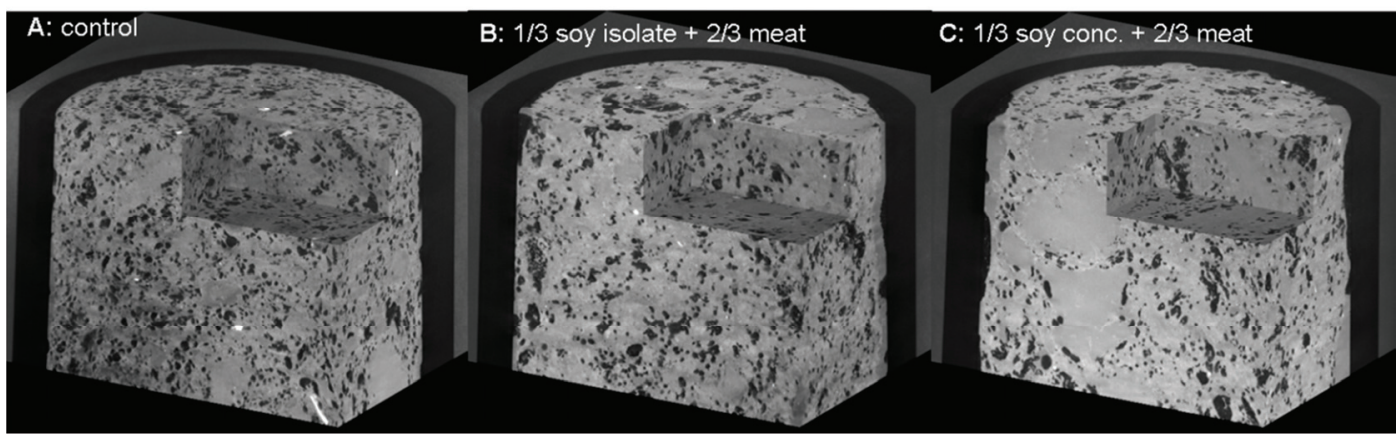

FIGURE 4. 3D visualization of the reconstructed phase contrast data set of the heat treated control emulsion (A) and the emulsions prepared with soy isolate (B) or soy concentrate (C). The dark ring surrounding the samples is the sample tube. The samples components are separated due to differences in electron densities: protein phase (grey), fat (dark).

From the 3D visualizations it can be observed that substitution of meat proteins with soy proteins changes the structure of the protein phase (grey) and affect the fat emulsification (dark spots) . In the control emulsion the protein phase appears homogeneous and the fat globules are relatively small and evenly distributed in the sample. Compared to the control the samples prepared with soy protein have larger and more coalesced fat globules indicating that the meat proteins have better emulsification properties compared with the soy proteins. The protein phases in the emulsions prepared with soy are in general more heterogeneous compared to the control, but differences between soy isolate and soy concentrate is also observed. In the emulsion prepared with soy concentrate large areas with high intensity aggregated proteins (light grey) are observed. This indicates the differences in functionality of soy protein derived from either isolate or concentrate. As a consequence of the decreased emulsification properties and the heterogeneous aggregated protein phase the emulsion stability is affected resulting in shrinkage of the emulsion structure during cooking and in separation of cooking loss. The shrinkage is observed as a slip between the emulsion and the sample holder in Fig $4 \mathrm{~A}+\mathrm{B}$. The cooking loss is visible as a homogeneous grey phase between the sample holder and the emulsion.

From the 3D data sets the observed difference in microstructure can be further explored by data segmentation and a quantitative analysis of the full sample volumes. The data segmentation will be performed as presented in our previous papers (Einarsdottir et al., 2014; Miklos et al., 2015) and is expected to include the quantitative parameters: object volume, surface area, porosity, degree of anisotropy, particle size distribution of the emulsion components. Further the amount of cooking loss will be estimated.

\section{CONCLUSION}

$\mathrm{X}$-ray $\mu \mathrm{CT}$ has been succesfully used in studies of the microstructure of a wide range of foods, but show limitations in the case of food structures with low variation in mass densities such as a meat emulsion. Compared to absorption X-ray tomography, X-ray phase contrast tomography offers improved image contrast. In this study it was demonstrated that X-ray phase contrast measurements of meat emulsions enabled visualization of not only the main sample components protein and fat, but also variations in the protein network caused by the different functional properties between meat and soy proteins. 


\section{ACKLOWLEDGEMENTS}

The authors acknowledge financial support through the NEXIM research project founded by the Danish Council for Strategic Research (contract no. 11-116226) within the Program Commission on Health, Food and Welfare.

\section{REFERENCES}

Bech, M., Jensen, T.H., Bunk, O., Donath, T., David, C., Weitkamp, T., Le Duc, G., Bravin, A., Cloetens, P., \& Pfeiffer, F., "Advanced contrast modalities for X-ray radiology: Phase-contrast and dark-field imaging using a grating interferometer," Zeitschrift fur Medizinische Physik, 20, 7-16 (2010a).

Bech, M., Bunk, O., Donath, T., Feidenhans'1, R., David, C., \& Pfeiffer, F., "Quantitative x-ray dark-field computed tomography," Physics in Medicine and Biology, 55(18), 5529 (2010b).

Einarsdóttir, H., Nielsen, M.S., Miklos, R., Lametsch, R., Feidenhans'l, R., Larsen, R., Ersbøll, B.K., "Analysis of micro-structure in raw and heat treated meat emulsions from multimodal X-ray microtomography," Innovative Food Science and Emerging Technologies, 24, 88-96 (2014)

Jensen, T.H., Bottiger, A., Bech, M., Zanette, I., Weitkamp, T., Rutishauser, S. et al., "X-ray phasecontrast tomography of porcine fat and rind," Meat Science, 88, 379-383 (2011).

McDonald, S. A., Marone, F., Hintermuller, C., Mikuljan, G., David, C., Pfeiffer, F. et al., ”Advanced phase-contrast imaging using a grating interferometer," Journal of Synchrotron Radiation, 16, 562-572 (2009).

Miklos, R., Nielsen, M.S., Einarsdottir, H., Feidenhans'l, R.K., Lametsch, R., "Novel X-ray phasecontrast tomography method for quantitative studies of heat induced structural changes in meat," Meat Science, 100, 217-221 (2015)

Nielsen, M. S., Lauridsen, T., Thomsen, M., Jensen, T. H., Bech, M., Christensen, L. B., et al., "X-ray tomography using the full complex index of refraction," Physics in Medicine and Biology, 57, 5971 (2012).

Nielsen, M.S., Christensen, L.B., Feidenhans'1, R., "Frozen and defrosted fruit revealed with X-ray darkfield radiography," Food Control, 39, 222-226 (2014)

Pfeiffer, F., Kottler, C., Bunk, O., David, C., "Hard x-ray phase tomography with low-brilliance sources," Physical Review Letters, 98, 108105 (2007)

Pfeiffer, F., "Milestones and basic princimples of grating-based X-ray and neutron phase-contrast imaging", AIP Conference Proceedings, 1466, 2-11 (2012).

Shoeman, L., Williams, P., du Plessis, A., Manley, M., "X-ray micro-computed tomography ( $\mu$ CT) for non-destructive characterisation of food," Trends in Food Science \& Technology, doi: 10.1016/j.tifs.2015.10.016 (2015)

Weitkamp, T., David, C., Kottler, C., Bunk, O., Pfeiffer, F., „Tomography with grating interferometers at low-brilliance sources", International Society for Optics and Photonics, pp. 6 (2006).

Weitkamp, T., Diaz, A., David, C., Pfeiffer, F., Stampanoni, M., Cloetens, P. et al., "X-ray phase imaging with a grating interferometer," Optics Express, 13, 6296-6304 (2005). 